\title{
Motivation States for Physical Activity and Sedentary Behavior: Desire, Urge, Wanting and Craving
}

Matthew A. Stults-Kolehmainen ${ }^{1,2 *}$, Miguel Blacutt ${ }^{2}$, John B. Bartholomew ${ }^{3}$, Todd A. Gilson', Garrett I. Ash ${ }^{5,6}$, Paul C. McKee ${ }^{7}$, Rajita Sinha ${ }^{8}$

${ }^{1}$ Bariatric and Minimally Invasive Surgery Program, Yale New Haven Hospital, New Haven, Connecticut, United States of America

13 2Department of Biobehavioral Sciences, Teachers College, Columbia University, New York, New

14 York, United States of America

${ }^{3}$ Department of Kinesiology and Health Education, The University of Texas at Austin, Austin,

16 Texas, United States of America

${ }^{4}$ Department of Kinesiology and Physical Education, Northern Illinois University, DeKalb, Illinois, United States of America

${ }^{5}$ Pain, Research, Informatics, Medical Comorbidities and Education Center (PRIME), VA

Connecticut Healthcare System, West Haven, Connecticut, United States of America

${ }^{6}$ Center for Medical Informatics, Yale School of Medicine, New Haven, Connecticut, United States of America

${ }^{7}$ Department of Psychology, Southern Connecticut State University, New Haven, Connecticut, United States of America

\section{* Correspondence:}

Matthew Stults-Kolehmainen

Matthew.stults-kolehmainen@ynhh.org

Keywords: urge for movement, desire, physical activity, exercise, motivation, sedentary activity, motivation states, conceptual analysis 
Desire, Urge and State Motivation

\section{Abstract}

To better explain daily fluctuations in physical activity and sedentary behavior, investigations of motivation are turning from social cognitive frameworks to those centered on affect, emotion and automaticity, such as the Affect and Health Behavior Framework (AHBF), Integrated Framework and Affective-Reflective Theory (ART). This shift has necessitated: a) reexamination of older theories and their constructs, such as drives, needs and tensions and $b$ ) an inspection of competing theories from other fields that also attempt to explain dynamic changes in health behaviors. The Dynamical Model of Desire, Elaborated Intrusion Theory and others commonly share with AHBF the idea that human behavior is driven strongly by desires and/or the similar concepts of wants, urges, and cravings. These affectively-charged motivation states (ACMS) change quickly and may better explain physical activity behavior from one moment to the next. Desires for movement predominantly derive from negative but also positive reinforcement. Data from clinical populations with movement dysfunction or psychiatric disorders provides further evidence of these drivers of movement. Those with Restless Legs Syndrome, akathisia, tic disorders and exercise dependence all report strong urges to move and relief when it is accomplished. Motor control research has identified centers of the brain responsible for wants and urges for muscular movement. Models elaborated herein differentiate between wants, desires, urges and cravings. The WANT model (Wants and Aversions for Neuromuscular Tasks) conceptualizes desires for movement and rest as varying by magnitude, approach or avoidance-orientation (wants versus aversions) and as occupying independent dimensions instead of opposite ends of the same axis. For instance, one hypothetically might be in a state of both high desire for movement and rest simultaneously. Variations in motivation states to move and rest may also be associated with various stress states, like freezing or fight and flight. The first validated instrument to measure feelings of desire/want for movement and rest, the CRAVE Scale (Cravings for Rest and Volitional Energy Expenditure) is already shedding light on the nature of these states. With these advances in theory, conceptual modelling and instrumentation, future investigations may explore the effects of desires and urges for movement and sedentary behavior in earnest. 
Desire, Urge and State Motivation

Introduction

The question of what motivates human movement, physical activity and sedentary behavior can trace its origin back to the time of the ancient Greeks. Aristotle was of the conviction that movement was the outcome of two faculties working together, practical reason and desire (1-4). When weighing the contribution of each, he concludes that the "mind is not of itself sufficient to engender motion, but instead relies upon appetite" $(1,2)$. Furthermore, he refines the roles of desire by stating its main function is to jumpstart movement. He states succinctly, "It is manifest, therefore, that what is called desire is the sort of faculty in the [mind] which initiates movement" $(1,2)$. In other words, it is desire that actually "prick[s] practical intellect" and sets muscular movement in motion $(1,2)$. Aristotle's focus, therefore, was on the interaction of affective and cognitive factors to produce movement in the present moment.

In the last century, however, the emphasis has been on trying to understand the individual's stable disposition for physical activity or exercise and promoting these behaviors on the time frame of the week, month or longer. Exercise behavior has typically been studied within the scope of several frameworks, including the mechanistic, social cognitive, socioecological, and humanistic/organismic paradigms (5). These later traditions are mainly rooted in cognitivebased perspectives which likely exaggerate the "capacity and willingness [of humans] to make rational decisions in order to achieve desired goals" (6). They tend to underplay or ignore affective factors, even though these are tantamount for the initiation and refinement of much of human behavior $(7,8)$. For instance, only a few of these theories have considered the idea of desire or similar concepts. An exception seems to be Self-Determination Theory, (SDT), in which intrinsic motivation largely overlaps with craving/desire (9), and a lack of desire is a central feature of amotivation (5). Interventions based on cognitive constructs typically have low impact, as gauged by small effect sizes (10), and they have "modest utility as mechanisms of behavior change" (11).

More recently, models have emerged that incorporate both conscious and unconscious, affective and deliberative factors affecting muscular movement in the present moment. Dual process theories, such as the Affect and Health Behavior Framework (AHBF), clearly articulate the role of desires and cravings in instigating various health behaviors, such as exercise and smoking $(9,11)$. This model also highlights the central role of hedonic motivation. Williams and Evans (9) state, "people typically crave/desire what they previously had a positive response to". The central role of cravings in the formation and maintenance of "habit loops" has been the focus of a New York Times best-selling book (Atomic Habits) (12). Nevertheless, no formal theories exclusive to the domain of physical activity highlight the role of desires or urges for muscular movement $(5,6,11)$.

Among those specific to movement, perhaps the theories most aligned with the idea of desires and urges are the Affective-Reflective Theory (ART) (6) and the model from Conroy and Berry (13). Both of these models exist within the dual process framework and attempt to balance cognitive and affective processes to explain physical activity, and more specifically, exercise, at the moment activity is initiated (6). A relevant construct within both theories is the concept of the action impulse, which is the direct intermediary between automatic affective processes and movement behavior. These models do not specify, however, if impulses are conscious and felt. In motor control, the idea of desires for movement has been formally articulated as "wants", which emanate from the inferior parietal lobule of the brain (14). In medicine, the concept of restless "urges" has been studied for decades (15). The concept of "appetence" (i.e., strong and 
provoking desires for movement) has shed light on mechanisms of addiction (16). In musicology, the concept of "groove" describes the ability of music to generate feelings of urge to move (17). There appears to be considerable overlap in the concepts of desires, wants, urges and related constructs, yet they seem to vary by the dimensions of magnitude, specificity to movement behavior, whether the desire is conscious and felt, as well as valence. However, all these concepts might commonly be characterized as affectively-charged motivation states (18) and associated feelings that signal a pressing need to approach or avoid a state of muscular movement (or, conversely a state of rest).

At this time, no previous analysis or review has attempted to evaluate, synthesize and expand on these motivation states, despite their prevalence in several intersecting literatures $(2$, $5,6,9,14,16,19-22)$. In fact, most of the research on physical activity and cravings/desires investigates the efficacy of exercise to thwart cravings for other maladaptive behaviors, such as cigarette smoking or alcohol consumption (23). Therefore, the objectives of this conceptual analysis are the following. 1) To describe the theoretical basis of desire as a primary motive of movement as well as sedentary behavior. 2) To provide evidence that such desires/urges exist and may be felt consciously. 3) To clarify terminology and the overlap between desires, urges, and cravings for movement. 4) Lastly, we aim to model relevant situations and emotion states associated with fluctuations in desires to move and rest and move/rest interactions. This paper is not intended to describe a multi-factor model of desires for rest / movement, such as ART or AHBF, but to more clearly highlight the important role of desires as they currently fit in established models (e.g., AHBF) or how they might naturally be included in similar models (e.g., ART). We also do not aim to describe in detail interactions between desires/urges and other factors relevant in active behaviors, such as goals, intentions and other cognitive-related constructs, which is beyond the scope of this current analysis.

\section{Discussion}

\section{Drives, tension, reinforcement and reward}

\section{a. Hull and Drive Reduction Theory}

Early studies of motivation conceptualized behavior as a function of instincts, drives, needs and tensions (19) (see Ford (24) for a review). McDougall (25) was instrumental in defining instinct as a function of "native human propensities" interacting with motor and cognitive "native abilities". When propensities are stimulated by the environment they result in "an active tendency, a striving, an impulse, or drive towards some goal". In Drive Reduction Theory, Hull (26) described drives (energizers) as arising from innate physiological needs, such as the needs for water, food, air, and sexual activity. Physiological deprivation of these needs results in hunger, thirst, etc. and associated subjective feelings of tension (e.g., being hungry, thirsty). These felt tensions push those affected into action, and the amount of drive is proportional to the intensity of the resulting effort to satisfy the need. Drive reduction theory has poor performance in explaining complex human behavior, such as why humans willingly engage in strenuous and exploratory behavior that does not directly satisfy simple physiological needs (e.g., climb mountains). Drive reduction theory also includes a description of secondary drives, such as the drive for earning money, which are learned through conditioning (27). 
Desire, Urge and State Motivation

166

167

168

169

170

171

172

173

174

175

176

177

178

179

180

181

182

183

184

185

186

187

188

189

190

191

192

193

194

195

196

197

198

199

200

201

202

203

204

205

206

207

208

209

210

211
The work of Kurt Lewin and his contemporaries provided an important basis for the study of desires and urges. Lewin simply thought of human behavior as an interaction of the person with their environment, varying by the place of the person in an inner "life space" or dynamic field $(6,28,29)$. This field incorporates a constellation of various needs, goals and motives - all changing with the situation - even on a moment by moment basis. In his Force Field analysis, driving and restraining forces act on a person to change behavior by propelling "locomotion" through a psychological field or environment, thus achieving an equilibrium. Lewin also described what he called "psychic tensions" in this field, which are "states of readiness or preparation for action" (29) - not undesirable stress or strain. These emerge in response to a need, want or some other stimulus, manifest as "intention or desire" to carry out a specific task and are "released" when that task is completed $(7,29)$. Less recognized is Lewin's work on satiation of tensions with his protege, Anitra Karsten. She observed that desire to complete various movement tasks was indeed related to tension, and as a movement was repeated the tension dissipated and desire diminished - a state of satiation resulting in the behavior ending (30). If the movement was forced to continue, the participant developed a great aversion to the task. Lewin saw this as a transition from psychological hunger to satiation to "oversaturation" and even related it to burnout - an "exhaustion of the will to work" $(31,32)$. Importantly, satiation following constant repetition of a task was not due to muscular fatigue but simply a lack of desire.

\section{c. Hedonic pleasure and reward}

From a simple behaviorist perspective, the key to motivation is reward $(9,33-35)$. In short, actions are repeated when reinforced - regardless as to whether this reinforcement occurs internally or from outside of the individual. There are two primary means of reward: positive reinforcement (providing a pleasurable stimulus) and negative reinforcement (taking away a negative stimulus). The strongest rewards follow those behaviors that result in both forms of reinforcement (34). While the concept of the current study concerns human perceptions and behaviors, it is easier to demonstrate principles of reward with rodents. Imagine a rat who has been denied nourishment and is growing hungry. Providing it with highly palatable food will reduce the pangs of physical deprivation, which is negative reinforcement $(36,37)$. This food also provides an immediate positive reinforcement as it stimulates sensory responses that activate neural pleasure centers. If the food was acquired by pressing a lever (a muscular movement) this behavior will be highly reinforced (34). Consequently, the rodent will continue to press the lever many times. Under conditions of severe hunger, this rodent will be motivated to contract its musculature with greater intensity $(38,39)$ in the effort to counter the aversive stimulus of hunger and in anticipation of a pleasurable reward. Such principles apply to humans as well. In neuroeconomics, the strength, persistence and vigor of muscular movements is considered a key predictor of what individuals' value, find rewarding and prefer in their everyday choices (40).

However, pressing a lever, like any type of physical activity, cannot be repeated indefinitely (33). The metabolic cost of movement (e.g., lactate) eventually sets in, resulting in painful and punishing sensations (41-43). Indeed, with growing fatigue, the punishment of movement becomes more aversive than hunger. Hence, movement is stopped, and rest occurs, which is yet another example of negative reinforcement as the cessation of muscular movement removes the negative stimulus. In this illustration, movement is merely instrumental $(19,38)$; it 
Desire, Urge and State Motivation

212 is completed to acquire an outside source of reward (food) and remove hunger while avoiding 213 excessive fatigue. Thus, from a behaviorist perspective, movement itself is not the source of pleasurable sensations, but it may be a source of considerable aversive sensations.

Is it possible that the act of movement itself may result in positive reinforcement? Many species will run purely for the sake of moving $(35,44,45)$ and will even press a bar repeatedly to gain access to a running wheel $(46,47)$. However, it is debatable whether movement itself is naturally reinforcing in humans $(44,48)$. Based on their empirical evidence, Cacioppo and colleagues (49), Cabanac $(50,51)$ and others $(48)$ have argued that muscular movement must be reinforcing because it is the primary method of acquisition and consumption of many pleasurable stimuli, repeated many times over one's life. In short, where movement is useful it must also be pleasant and wanted, at least occasionally. Furthermore, some human behaviors are fundamentally motivated even when there is no specific reward associated with them, such as exploration, perhaps because of the occasional discovery of a pleasurable, unconditioned stimulus (48). The extent to which these arguments are valid in a modern world, where machines can do both our labor and exploration, is uncertain. Nevertheless, it is generally accepted that voluntary physical activity may be agreeable $(44,52)$, and there is an abundance of observations that some individuals even frolic, particulary children (53). That is, they move with joy and exuberance $(53,54)$.

In regards to structured exercise, the largest body of human research has centered on the potential of exercise to provide both immediate (mood, enjoyment) and delayed (body image) positive reinforcements, both directly and indirectly (e.g., social interactions) (41). Exercise increases vigor and feelings of positive well-being in both normal and clinical populations (55). The phenomenon of a "runner's high", a state of euphoria during or following endurance exercise, is linked to opioid binding in prefrontal/orbitofrontal cortices of the brain $(52,56)$. Exercise of almost any modality provides enhancements in affective tone, particularly during moderate intensity exercise and in the rebound period after strenuous exercise $(41,57)$. Variability in feelings of pleasure during exercise (but not afterwards) is a predictor of adherence to exercise programming $(58,59)$, which seems to indicate that for some individuals, physical activity is rewarding and reinforcing for future behavior. Some individuals even "like it vigorous", in other words, prefer a high level of intensity for their exercise (60) and find meaning and pleasure in the face of displeasure. Collectively, enjoyment, intrinsic motivation and affective attitudes about exercise appear to be key mediators in the relationship between affective responses to exercise and future activity behavior (59).

Movement is motivated not only by the optimization of pleasure, but by reducing displeasure (51). What is lacking in the extant literature, however, is a thorough consideration of physical activity as a negative reinforcer - that movement may serve to alleviate tension (9). Some research exists concerning the relief of negative affective states (i.e., poor mood, distress) $(61,62)$ and reduction in pain sensation (e.g., exercise-induced analgesia) (63). However, these mood states have largely been considered as arising from an external source (e.g., work stress, social anxiety, etc.). That is, the activity itself is not tied to the source of negative mood. In these cases, exercise is no more or less effective than other means to improve mood (64). As such, exercise is a choice no more compelling than relaxation practices, alcohol use, distraction (e.g., TV), and other forms of stress coping $(65,66)$.

However, might it be that some of these negative states may be derived from the lack of physical activity? That is, could there be a drive for physical activity that requires some degree of activity to satisfy the need $(19,48,67-70)$ ? One might propose that all humans are "hard 
Desire, Urge and State Motivation

wired" for movement for: a) instrumental reasons (e.g., foraging for food, seeking and building shelter, etc.), b) for play, which helps to develop physical traits, develop social skills and improve affective tone (53), c) for seeking out rewards and novel stimuli and new experiences $(4,48,71), d)$ for acquisition and processing of information (72) and other reasons $(50,51)$. Aristotle concluded that desires to move and rest are the drivers which "prick" these behaviors in the moments before they are initiated (1-3). Other early literature (summarized by Ekkekakis (41)) noted that humans have an "inherent propensity" or "drive for activity", a need for stimulation or "susceptibility". Many people even prefer electric shocks over total solitude (73). More pertinently, these drives are felt as a "necessity of body exercise", "volitional promptings" (74-79) or tension, perhaps similar to appetite $(16,36,80)$. Particularly under restrained conditions (i.e., prolonged sitting) humans feel "intense uneasiness or craving" or "pressing readiness". Over 100 years ago, Williams James related the case of a girl that had a "morbid impulse" causing her to "walk, walk, walk" (81).

Almost anyone can identify with the discomfort of sitting for prolonged periods, feelings of being antsy, jittery, squirmy, restless and/or fidgety, and the relief provided by movement (82). Several slang terms are also associated with similar conditions and feelings, including being "cooped up", "stir crazy" or having "cabin fever". Those with low back pain disorders fidget and shift their bodies, sometimes multiple times every minute, in order to relieve pressure and avoid pain (83). However, systematic evidence for these behaviors are lacking in the current human literature. In post-behaviorism scientific literatures, such aversive sensations are generally linked to a limited number of phenomena, including urges associated with Restless Leg Syndrome (15), akathisia (characterized by a compelling need to be in constant motion) (84), hyperactivity $(39,85)$, anorexia $(39,86)$, forced bed rest $(87)$, loss of playtime/recess $(88)$, sudden decline in one's usual exercise routine (89), and exercise dependence/addiction $(16,21)$. Consequently, urges to move are well-documented in situations where such sensations are bothersome and unproductive.

\section{d. Processes of wanting}

An alternative framework for understanding wants/desires for physical activity and rest is the incentive sensitization model (ISM) of rewarding behaviors (52, 90-92). For any given pleasurable stimulus, the ISM proposes that there is both a hedonic like and an appetitive (motivational) want (93), which vary in intensity from transient desires to cravings or urges. Likes and wants are typically tightly linked (as in the case of food or drugs), but these constructs differ in several important ways. First, there is clear evidence that they are controlled by different neurobiological systems - opiod for likes and dopaminergic for wants $(52,92)$. Furthermore, likes and wants may become completely uncoupled, whereas in certain situations one may want to perform a particular behavior without necessarily liking it. For physical activity, this is most clearly relevant in the case of exercise dependence/addiction, in which individuals feel compelled to engage in physical activity even when it comes at great costs and is not enjoyable $(16,21)$.

The ISM also describes processes of wanting, including the prediction of when wants and desires may be whetted (stimulated), consummated and satiated. Wants are triggered by salient cues (irrespective of rewards), such as interoceptive sensations of tension, which may be amplified under conditions of physiological deprivation. In the case of physical activity, an example might be prolonged periods of unaccustomed sitting. Cues may also activate mental 
networks of associations (memory) to elicit urges (5). Furthermore, individuals become more sensitive to a reinforcing stimulus as it is repeated, causing the stimulus to be more salient and more attractive, leading to wanting the stimulus more. Flack and colleagues have investigated exercise protocols lasting 3 months under this paradigm, and found that more frequent exercise, or exercise with more total volume (i.e. $300 \mathrm{kcal} / \mathrm{day}, 5$ days/week) can increase the relative reinforcing value of exercise compared to sedentary activities in a group of untrained and overweight individuals $(94,95)$. It is unknown if physical activity, outside of exercise, can become more rewarding and salient with repeated exposure, particularly for those who are typically inactive.

The ISM model has several drawbacks. First, it was developed in examination of rewarding substances like food or drugs. However, physical activity may differ from these substances in that: a) the latter emanate from external sources, b) consumption is highly tied, at least initially, to the experience of pleasure, while physical activity may not be, c) they are subject to scarcity while movement typically is not and d) movement is required for the acquisition of the former. Moreover, given the great utility of movement, it must be accomplished in day-to-day life, and thus is likely wanted, even if is not necessarily liked (50, 51). Consequently, liking and wanting of physical activity may be loosely coupled for most of the population. Lastly, this model underplays the role of affect, which is discordant from the well-established literature describing relationships between movement and emotion $(7,11,62)$. Despite these downsides, the ISM model is valuable in emphasizing the importance of craving as an intermediary state prior to action, representing motivation and intent.

\section{Self-Determination Theory}

In the view of Roberts (96), the aforementioned theories of drive and behaviorism are "deterministic and mechanistic", which "view humans as being passive". Organismic theories, like Self-Determination Theory (SDT), and more specifically, the sub-theory of organismic integration theory, integrate and expand on the concept of human needs and drives, consider the person's goals and feelings and evaluate the person in a social context (97). The three basic psychological needs are competence, autonomy, and sense of relatedness. However, Deci and Ryan (98) state that self-determination itself is the "capacity or fundamental need to choose and to have choices, rather than reinforcement contingencies, drives, or any other forces or pressures be the determinants of one's actions". People who are self-determined act upon fully internalized motivations, categorized into three distinct drives: intrinsic motivation to know, to accomplish and to experience stimulation $(99,100)$. Performing movement for its own sake and for its enjoyment is considered intrinsic motivation $(5,19)$. Intrinsic motives can exert a powerful and long-lasting influence on exercise behaviors (101). Williams and Evans (9) explicitly distinguish between sources of motivation (e.g., to experience stimulation) versus the affective charge attached to a motivation state. They conclude that, "intrinsic motivation is typically an affectively-charged motivation state that involves either craving/desire or fear"; however, they also recognize that movement is accomplished in the absence of strong desire. According to SDT, behavior is also influenced by extrinsic motives, such as tangible rewards (e.g., trophies), or wanting to be someone specific (e.g., a highly competitive athlete), which are farther down on the continuum of self-determination. Nevertheless, these also can result in strong desires, as in

349 the case of having a strong, affectively-charged desire to perform sport because it is expected to 
result in strong social approval and the admiration of others (9). Ostensibly, one might have multiples desires at the same time, such as a desire for a reward (extrinsic) and a desire for movement itself (intrinsic). In this case, however, movement might be merely instrumental and secondary to the more pressing desire (19). Amotivation, on the other hand, is a state of no motivation, or a near-total lack of desire or drive to perform a behavior. Consequently, SDT appears to be a complimentary theory, likely concordant with the idea of wants or urges for

\section{Dual process theories}

\section{a. Affect and Health Behavior Framework (AHBF)}

The AHBF (9) outlines a dual process model in which learned automatic (unconscious) associations (A-system) and reflective/deliberative processes (R-system) work in concert to propel health-related behavior (102). In this model, "wanting" is considered automatic motivation as part of the A-system, along with the opposite construct, dread. Dread is a concept related to the emotion of fear - a motivational force that propels a person to move away from or avoid an aversive stimulus (103). Williams and Evans (9) distinguish these from desires, cravings and fear, which they label as affectively-charged motivation (18). These are the product of conflict between automatic impulses (e.g., wanting, dread) and reflective intentions and goals (R-system) (9). Despite these divisions between desire, craving and wanting in their model, the authors seem to also categorize the former two as part of wanting and all of these, together with dread and fear, as part of affectively-charged motivation states (ACMS).

The model provides an understanding, though incomplete, of how an individual might have motivation states for physical activity. They note that, "people typically crave/desire what they previously had a positive affective response to", which would seem to include physical activity. However, they later explain that these factors are typically only implicated with the experience of highly palatable food, sex, drugs, etc. (9). Physical activity is not considered a source of cravings/desire, but rather it is largely seen as a source of dread. In their example, exercise is frequently and automatically associated with fatigue and pain, thus resulting in aversion as the automatic motivation. This restraining force may come into conflict, however, with a long-term intention of going outside to run. Whether an exercise action prevails is also influenced by competing behaviors (e.g., watching TV) and one's current mood state and mental stress (62). Despite some lack of clarity in this model, it provides an important advancement in the exploration of desires and cravings in physical activity research.

Williams, Rhodes, \& Conner (11) later revamped and extended the AHBF in their integrated framework (IF or AHBF-IF). Several improvements are observed in this model. First, it more clearly structures the relationships of all included factors, with paths starting with affect proper (specific mood and emotions), leading to motivation states and ending with behavior. It highlights the role that incidental affect can have on physical activity behavior (104). Second, they collectively categorize wanting, desire, dread and aversion, so as to avoid the arbitrary divisions between these factors seen in the previous model. However, they relabel them as "hedonic motivation" as opposed to affectively-charged motivation states. A third strength of this revised model is that one can clearly delineate both the antecedents of affectively-charged motivation states (e.g., desires/urges) as well as their influence on behavior. Affectively-charged motivation states are seen in this model as proximally mediating the relationship between affect 
processing and behavior. As with other models discussed below, there is both an automatic and a reflective pathway, with affective processing and motivational processes occurring in both paths. Thus, the model supports goal-directed and purposeful motivation. Based on these improvements, more testable hypotheses may be formulated, and it is easier to generate examples of how desires might work in the real world. For instance, experiences of post-exercise affect (e.g., post-run euphoria) could result in an automatic association of running with pleasure. Anticipating this response again could lead to desires to run at another opportunity. On the other hand, the experience of inordinate work stress (incidental affect), resulting in poor mood, might activate automatic associations of exercise and excessive fatigue, resulting in an aversion to exercise, which squelches physical activity (62). Overall, the AHBF-IF is an improved multifactor model explaining how desires/urges may be generated and result in some movement behaviors - i.e., exercise.

Despite improvements, the AHBF-IF still has several limitations. A continued drawback with this model is that it is not specific to physical activity but generalized to all purposeful health behaviors (e.g., smoking). Also, when considering physical activity, the models primarily seek to explain purposeful, structured exercise behavior, and it's not clear if the model can explain the greater spectrum of physically active behaviors (i.e., task-specific movement, spontaneous movement, fidgeting). More significantly, cravings or desires specifically for movement are not considered in this model even though it opens the possibility that these exist. Because of the simplification and recategorization of affectively-charged motivation states ("hedonic motivation"), there remains ambiguity in the interaction between desires and dread for exercise behaviors. Furthermore, the model lacks a clear articulation on the role of restraining forces, such as the need or urge for rest and how these conflicts occur in the moment (8). Finally, the model does not provide an explanation for how affectively-charged motivation states, such as desires, interact with goals and intentions.

\section{b. Affective-Reflective Theory of Physical Inactivity and Exercise (ART)}

Several recent dual process models have focused specifically on exercise behavior, such as the Affective Reflective Theory of physical inactivity and exercise (ART) from Brand \& Ekkekakis (6) and a similar model from Conroy \& Berry (13). These authors similarly hypothesize that movement is the product of the interplay between two systems: a type-1 automatic process and a type- 2 process for reflective valuation $(6,13)$. They see the discordance between an actual state and "desired state" (i.e., exercising) due to driving forces and restraining forces, similar to the concept of tension systems from Lewin (28). In their model, an exercise stimulus elicits a spontaneous affective response (i.e., pleasure/displeasure associated with the activity) through type-1 processing, resulting in an action impulse. Following this, slower type- 2 processing is used to reflectively generate an action plan. The combination of the type-1 action impulse and type-2 action plan results in physical activity behavior. However, discordance can exist between the action impulse and the action plan. An example of this would be when a seated individual is exposed to an exercise stimulus (e.g., sees a person running), and immediately associates it with an aversive state (e.g., running is tiring - which is bad), which prompts the individual to remain sedentary. At this time, however, the individual also thinks about her/his doctor's advice to exercise more frequently. In this case, Brand and Ekkekakis (6) propose that the behavior that will follow depends on the availability of self-control resources, where a 
greater availability will result in the execution of the action plan (i.e., go exercise) instead of the action impulse to be sedentary.

There are limitations with the models from Brand \& Ekkakakis (6) and Conroy and Berry (13). The first is that the concept of the action impulse is poorly defined, but seems to relate to a variety of other concepts, including: a) Lewin's description of psychic tension (29)), b) the "prick" that was described by Aristotle (1-3), c) the concept of "wants" as defined in motor control $(14,20)$ or d) it may be interchangeable with the concepts of states of action readiness (SOAR), action tendency $(25,54,102,105)$, activation states or a "specific motive state" in the description of impulsive action $(4,8,105,106)$. Nevertheless, the authors note that, "core affective valence may have a direct, immediate impact on behavior through behavioral urges" (6). The second problem is that this theory was created to explain the complex behaviors of exercise and regimented physical activities - as opposed to the greater spectrum of physically active behaviors, including spontaneous physical activity (82). The third issue is that the model represents sedentary behaviors as typically contrasting with physical activity; restraining forces pulling against propelling forces to alternate from one behavior to the other (e.g., flipping a single switch). However, rest and activity may not be in direct opposition. Instead, there may be restraining and propelling forces for both rest and movement acting simultaneously (e.g, two separate switches, or even two dials) $(107,108)$. The practical consequence of these limitations relates to intervening for muscular movement at the moment actions are being processed and how this might be modified or done flexibly based on desires for rest as well. Indeed, the purpose of these dual urges, working in concert, may be to "potentiate sets of action schemas with equifinality" for adaptive behavioral flexibility (8).

\section{c. Dynamical Model of Desire and Elaborate Intrusion Theory}

Alternative multi-process models specifically highlight the powerful influences of wants/desires on human behavior. Hofmann and colleagues in their Dynamical Model of Desire (109-111) draw on a diverse literature, defining desire as "a psychological state of motivation for a specific stimulus or experience that is anticipated to be rewarding [which] may or may not be consciously experienced" (112). This model also defines two routes by which desires can influence behavior: a) an automatic, impulsive and unconscious route and b) a route in which desires emerge into consciousness, become felt (e.g., have a subjective sense of wanting/feeling wants), interact with working memory and "hijack" cognitive processing. In the view of Kavanagh and colleagues in their Elaborated Intrusion Theory (113) desire is "an affectivelycharged cognitive event in which an object or activity that is associated with pleasure or relief of discomfort is in focal attention...it can be referred to as a conscious wish or urge to gain pleasure, relieve discomfort, or satisfy a want or to engage in consummatory behavior associated with these outcomes." In this model, desire inherently involves cognitive processing and is often instigated by triggers (i.e., thoughts, cues, affect, physical needs) that result in spontaneous, conscious and intrusive thoughts. Regardless of the definition or the specific factors in play, Hofmann and colleagues (109) have found that over 50\% of a person's waking hours are filled with various desires (110). The most common desire is that for sleep, but desires abound for many rewarding stimuli: coffee, leisure, sex, and numerous other activities and objects (111). Desire for muscular exertion is considered to be one of the most fundamental desires (19). Unfortunately, only cravings for participation in sport activities has been systematically investigated $(109,111,114)$. In one exception, Katula and colleagues (115) investigated the 
Desire, Urge and State Motivation

desire to be stronger and increase fitness. In this study, it was found that adding an empowering psychological intervention to a traditional strength training protocol increased the desire to gain strength in older adults.

\section{d. Important contributions from motor control}

Up to this point, there has been little clarity on the issue of "action impulse" or "action readiness" and how they relate to the initiation of and wants for movement. Research in motor control appears to address this gap most adequately by investigating wants (e.g. often referred to as "intentions") and urges at the level of simple movements (e.g, standing up, moving a finger). This work began with Libet (20), who asked participants to remember the moment they became aware of their want to move. This study was ground-breaking at the time because the data demonstrated that individuals' neural preparation for movement (i.e., readiness potential) occurred before they became consciously aware of their want/intention to move. Matsuhashi and Hallet (116) improved on flaws in Libet's original study design and found that the intention to move goes through multiple layers of awareness and enters consciousness $1.42 \mathrm{~s}$ prior to actual movement initiation. The authors also found evidence of a "point of no return", which occurs when the want/intention to move cannot be vetoed- an urge. Wants for movement have a neurophysiological basis and seem to originate in the supplementary motor cortex (SMA), preSMA, posterior parietal cortex (PPC), pre-motor area, motor cortex, intraparietal sulcus, and in the insular cortex (14, 117-119). Neuronal activity in the SMA precedes the conscious awareness of wanting/intention to move by $700 \mathrm{~ms}$ and predicts it with $80 \%$ accuracy (117). Furthermore, Desmurget and Sirigu found that the inferior parietal lobule is responsible for the preparatory "wanting to move", while the mesial precentral area is responsible for the more powerful "urge to move" (14). Collectively, the readiness potential and/or the conscious awareness of wanting to move might be referred to as the "action impulse".

\section{Defining, categorizing and describing desires/urges to move and rest}

It is evident at this juncture that there is a multitude of evidence that desires/cravings exist, but progress is still impeded by a lack of conceptual organization and instrumentation. The first issue is the abundance of related, yet distinctive, terminology - including the considerations above but also terms from Frijda and colleagues work on states of action readiness (SOAR), such as motor intention, longing, striving, "current concerns", action tendency, urgency, control precedence, awareness of action readiness and "non-overt inclination" (4, 7, 102, 106, 120-122). Part of the confusion seems to stem from considerations of motivations states (e.g., urgency (121)), processes (e.g., "wanting", (90)) and distinct, concrete felt perceptions and other unfelt forces (a "want", an "urge"). To tackle this issue, the concepts of wants, desires, appetence, groove and the action impulse (i.e., action readiness) were all plotted on a field distinguishing them by ostensible differences in valence (negative or positive tension) and their specificity to movement (see Figure 1). The concept of groove, for instance, is specific to a felt need to move, and is ostensibly conceived as a positive force or tension (17). It is highly contextual to the influence of music, however. Urges to move, most cited in work on Restless Legs Syndrome, are highly specific in this context to muscular movement but are clearly gauged as a negative tension. Patients with Restless Leg Syndrome, other variants such as Restless Arm or Mouth Syndrome, and Tourette's Syndrome report pressing, involuntary and bothersome urges to move 
and/or stretch that are often temporarily supressed but eventually released (123-125). Appetence is highly specific to movement, but neutral in feeling in the same sense that appetite may be either present or lacking but distinct from the pangs of hunger (16). Wants have also been highly related to movement in the motor control literature, but usually are considered neutral in valence. Desires, on the other hand, have lacked specificity to movement and rest and have a positive connotation. Finally, it must be considered that constructs such as desire and want, while in this context highly concrete (e.g., they are discreet, observable and measurable) are typically used in a much more abstract and conditional sense (i.e., she wants to go for a walk after work). This makes completing literature reviews in the area difficult because keyword searches result in tens of thousands of irrelevant returns.

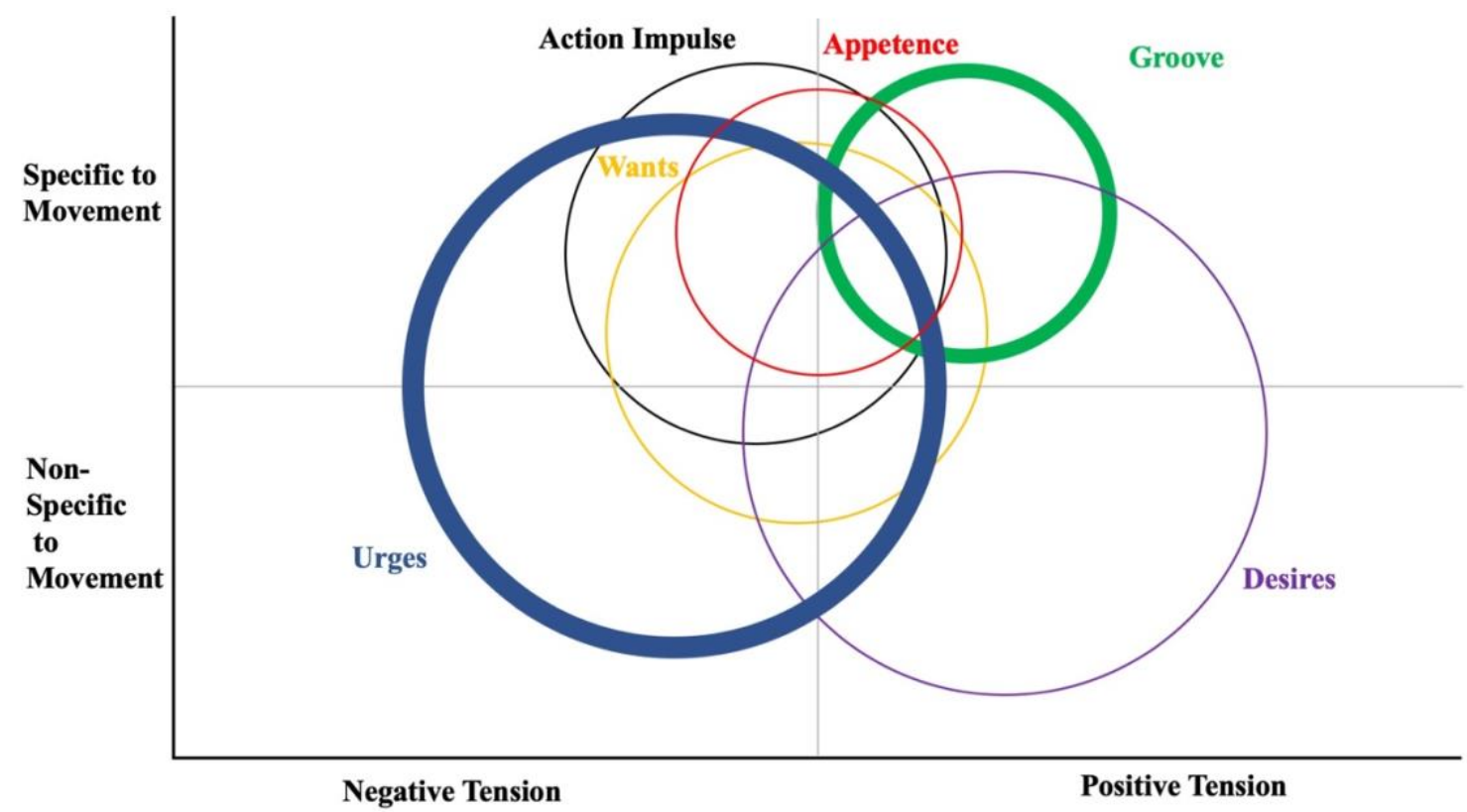

544
Figure 1. Venn diagram illustration of some affectively-charged motivation states (ACMS; urges, wants, appetence, groove, desires and action impulses) as they vary by specificity to muscular movement and valence of the tension. Some concepts originated with movement (i.e., groove, appetence) while others are generally applicable to a multitude of reinforceable behaviors. Circle size denotes degree to which the state covers multiple quadrants. Thickness of circle line denotes prevalence of theme in current literature. [Not all ACMS constructs are included.]

As mentioned above, there is a question about how desires/wants to move relate to desires for contrasting behaviors, such as being sedentary or resting. Thus far, the focus has been on motivation states for movement, but special attention is needed to elucidate whether restrelated wants should be conceived as a restraining force acting simply against movement or a separate dimension of wants interacting flexibly with those to move. In his early work, Frijda $(54,105)$ characterized rest simply as a state where there is an "absence of action readiness", a feeling of not needing to do anything, rather than a separate dimension or system. However, there is reason to believe that rest and movement wants/urges operate in separate planes/continua and are not opposite ends of the same axis. First, as indicated above, other researchers have separated these into distinct desires, asking respondents to report whether they want to sleep, or rest or engage in movement activities $(19,109,111)$. Indeed, sleep likely has its own drive (26). 
Second, such conceptualization of desires and rest as separate factors was demonstrated by a recent factor analysis (108). Finally, the idea of separate systems for rest and movement desires seems to be concordant with other similar work describing separate "go" and "no-go" (107) and appetitive versus defensive systems $(8,126)$. Thus, it appears reasonable that one can approach or avoid both desires for rest and movement separately (8). In other words, rest and movement desires together do not correspond to a simple approach/avoidance for movement.

Conversely, it is proposed that there is approach/avoidance orientation for each system (rest and move) which corresponds to wants and aversions for each action (49). These forces, in turn, vary by strength as well. One might consider the concept of dread as being more than the intense lack of urge to be in a state of movement/rest (i.e., a 0-point) but also an active avoidance of those states $(9,103)$. For instance, those with chronic low back pain and/or kinesiophobia exhibit fear and dread of movement and make attempts to actively avoid it, when possible, to prevent painful sensations (127). Consequently, it appears that a dimension of avoidance/approach, each of which varies by magnitude or level of activation/deactivation, is more appropriate than categorizing them by negative/positive valence (11, 128-130). Furthermore, wants/desires, while typically affectively-charged, are independent from emotion $(9,11,18)$. In contrast, wants/desires appear to often be triggered by and result in various emotion states (105). Regarding magnitude, desires/wants ostensibly can range from very weak to very strong. In motor control, strong wants are labeled as "urges", and importantly, urges are closer to the actual manifestation of movement than wants (14). Figure 2 provides an intermediary categorization how wants, desires, urges and cravings, the most described motivation states, might be conceptually organized to explain movement and rest behaviors. It explicitly divides move and rest wants/urges into separate categorizations. A substantial shortcoming of the simple categorization of desires and urges in Figure 2 is that it does not consider how desires for rest and movement can interact to produce flexible and adaptive behavior.

\begin{tabular}{|c|c|c|c|}
\hline \multirow{3}{*}{ MOVE } & & Wants (mild) & Urges (intense) \\
\hline & Approach & Desire(s) to move & Craving(s) to move \\
\hline & Avoid & Aversion(s) to move & Dread* to move \\
\hline
\end{tabular}

Wants (mild)

\begin{tabular}{l|c|c|c|}
\hline \multirow{2}{*}{ REST } & & Wants (mild) & Urges (intense) \\
\cline { 2 - 4 } & Approach & Desire(s) to rest & Craving(s) to rest \\
\cline { 2 - 4 } & Avoid & Aversion(s) to rest & Dread* to rest \\
\hline
\end{tabular}

Figure 2. Want/urge motivation states specific to the domains of movement and inactivity behaviors: Approach/avoidance orientation vs Intensity. This is a simple categorical model preceding the model described in Figure 3. * Singular and plural for impulses and dread (multiple instances of dread).

How desires to move and rest interact might be best visualized in an orthogonal perspective. Given the logic above outlining separate dimensions or systems for move and rest, 
it's proposed that one might occasionally occupy conditions in which one is high in both desires to move and rest - as well as low in both. The same may be true for avoidance orientation (e.g., high in the need to avoid both movement and rest, i.e., dread) (131). Figure 3 plots the WANT (Wants and Aversions for Neuromuscular Tasks) model. This is a descriptive, circumplex model $(132,133)$ of affectively-charged motivation states (i.e., ACMS; desire, urges, aversions and dread) to move and rest, the continua of which are positioned orthogonally from each other. Importantly, and unlike other models, both desire and dread are modeled on the same continuum as opposed to being separate constructs $(9,11)$.

The WANT model was designed to plot, categorize, and help to describe potential situations in which desires/urges to move/rest may occur, as well as associated emotional phenomena that may be generated in those circumstances. For instance, simultaneously experiencing very high rest and very high move wants/urges might occur in situations, such as: a) having just won a competition and wanting to celebrate, but also being physically exhausted, b) being torn between the need to workout or rest / have a meal, c) suddenly becoming injured in the middle of competition, d) overtraining, or other situations in which one might feel conflicted. Being low in both move and rest wants/urges, conversely, would be closer to the intercept of these axes, a state of deactivation that might be similar to a state of depression (4) or possibly a meditative state of mindfulness and stillness. The WANT model also delineates avoidant motivation states characterized by feelings of not wanting to rest to move, in other words, having an aversion or dread. Relevant emotional outcomes in these quadrants include a variety of stressor states, like fight or flight (105). Conversely, one might experience freezing behavior in the face of danger, which might be characterized as motivational states high in dread for both movement and rest (4). Frijda (4) argues that in such situations, there is no action readiness and individuals face "motivational null states" because "no meaningful action can be conceived".

The WANT model provides several advances. First, it explicitly describes affectivelycharged motivation states (ACMS) along several dimensions: a) move vs rest axes, b) approach (desire/urge) vs avoidance (aversion/dread) orientation and c) relative strength of desire (inner vs outer circle symbolizing desire vs urge strength) with a 0 point and a hypothetical maximum. This allows the reader to determine relations more easily among variables. There is also predictive value to this taxonomy. As suggestive above, a score high in move and low in rest might be predictive of a highly energized state of action readiness for action. Frijda (54) describes excitement as "impulse towards restless movement, with frequent changes in direction" and not being able to sit still (105). Likewise, exuberance is "impulse towards enhanced movement scope and movement abundance" with those selecting this emotion reporting, "I wanted to move, be exuberant, sign, jump, undertake things" $(54,105)$. Therefore, the model permits categorization of various situations, emotions and feelings as described above by quadrant (e.g., high move/low rest; high move/high rest). One can also map transitions, both sudden and gradual, in move/rest desires and placement in "fuzzy" situations (e.g., feeling really tired but also relying on one's body to get home after work) $(132,133)$.

The utility of the WANT model to formulate testable hypotheses or predict future states or behaviors is yet to be determined. How specific desires/urges (or combination of desires) interact with other factors to ultimately drive behavior is not modeled. Pacherie (120) and Frijda $(4,106)$ point to the fact that desires and states of action readiness (SOAR) do not absolutely determine behavior. Rather, desires are highly flexible in their behavioral outcome since many different actions can result from the consummation (or not) of desire (4). Such flexibility is likely advantageous and adaptive. This being said, the relative strength of competing urges plays a part 
643 in behavioral choice $(109,111)$. Deliberative factors also can act on specific desires to enhance 644 or minimize their impact (134). Lewin's force field analysis seems to suggest that a multitude of 645 forces work in tandem to help an individual achieve a state of equilibrium $(6,29)$, and this varies by a variety of individual needs, motives and situational factors which are beyond the scope of this model to include. From a neuropsychological perspective, how one behaves might primarily be a function of dopamine regulation, as in the "go" and "no go" model (107). While the WANT model is not high in predictive value, it is intended to be helpful for understanding the nature of desires/urges before adequate path models can be created.

651

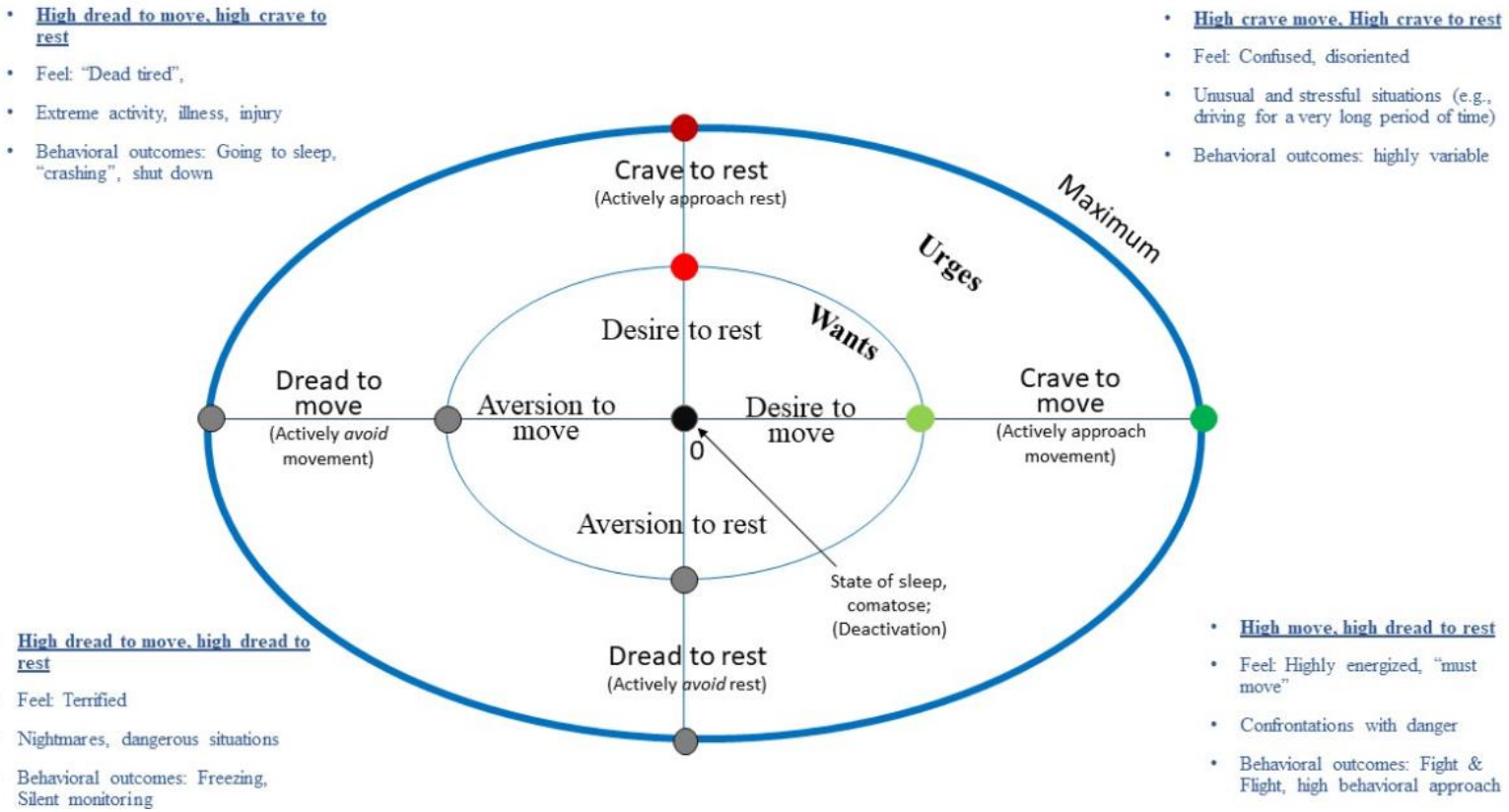

Figure 3. WANT (Wants and Aversions in Neuromuscular Tasks) circumplex model of affectively-charged motivation states (ACMS, i.e., wants, urges, aversions and dread) to move and rest. Interactions between these factors are associated with a variety of situations, emotions and psychological phenomena.

\section{Future research}

Research on desires or urges to move and rest is still in formation, and many avenues of research exist to realize its potential. To move forward, the following 10 areas should be considered.

1) While some progress has been made in defining desires and urges, how they relate to each other, and how they may influence physically active or sedentary behaviors, there are no systematic literature reviews in this area of inquiry.

2) The fundamental nature and descriptive quality of desires/urges to move still needs clarification. One basic issue relates to conscious awareness of desires/urges to move and how they are experienced or felt $(105,134)$. Are they felt as positive or negative, intrusive, and/or unwanted? Do they vary from young to old age? How frequently do they occur and how quickly 
672 can they change (22)? Are they more prominent during the acquisition or solidification of 673 physical activity habits $(12,135)$ ?

3) The WANT model (Figure 3), describing the orthogonal nature of desires to move and rest needs testing and empirical validation (133), the beginning of which is described in a recent paper (108). One drawback is that the model does not explicitly include an additional dimension of affect (e.g., pleasure/displeasure), chronicity (i.e., a single urge versus constant craving), or effect on motor behavior, which may necessitate refinements of the model.

4) Is there a threshold of want/urge magnitude to initiate movement, as suggested by the motor control research (14), and how does this relate to conscious awareness of the desire or urge (20)? The definition of "maximum" should also be clarified, whether that is defined psychometrically (e.g., feel "more than ever"), cognitively (i.e., the urge dominates thoughts) or behaviorally (e.g., motor actions have been initiated).

5) There is an obvious lack of a model, specific to movement and rest, to expound on the antecedents of desire and the varying impact on behavior, which could help to create testable hypotheses for future investigations. Such a model would be best fashioned in light of the multiple disciplines that have a shared interest in desires/urges to move, such as exercise psychology, motor control, clinical medicine and psychiatry $(9,14-16,21,84)$. Another possibility is that models, such as AHBF (11), could be slightly modified based on the observances from the WANT model (Figure 3). Such a model may consider the bi-directional nature of wants and urges with affect, emotion and mood. Can unsatisfied and unremitting urges and cravings exponentiate through worsening mood in a cyclic fashion? Understanding the complex relationships between these factors has significant implications in movement-based interventions.

6) The processes primarily described here predominantly relate to automatic and impulsive processes, but much needs to be done to formulate how desires/urges interact with deliberative (reflective) processes. Certainly, impulses can be overridden by higher order cognition (e.g., goals) (108) and desires can relate directly to goals (22). Feige (70) suggests that motivation for physical activity is a 5-level hierarchy, with drives to be active forming the foundation and goals and values in the highest level. These interactions have already been briefly detailed by theories, such as ART and AHBF, but also by: a) the Model of Goal Directed Behavior, in which desires interact with intentions to pursue a goal (136), b) the Grounded Theory of Desire and Motivated Behavior, in which environmental cues can spark memories, cognitions and mental reenactments, which generate desires (137), and c) the Elaborated Intrusion Theory, in which suppression of desire-related thoughts can lead to stronger desires (138). Interactions between desires/urges and deliberative processes are also prominent in research on clashes between these constructs, as in work on: a) want-"should" conflicts (139), b) goal-desire conflicts (134), and c) desires, reasoning and self-regulatory failure (140). To summarize, there appears to be bidirectional and dynamic relationships between desires and goals; desires can hijack thoughts, be diminished by thoughts, work with thoughts towards a goal or undermine a goal.

7) One question yet to be resolved is concerning a hierarchical typology for desires to move. More specifically, how do we distinguish between the human need to move for the sake of 
Desire, Urge and State Motivation

movement (primary desires) or simply to acquire something or accomplish some other task (secondary desires) (19)? For instance, it is a common sensation to feel the urge to move when needing to urinate (141), but this urge is secondary to the primary motive. More information is needed on how wants to move relate to wants for structured exercise or "working out", getting stronger, becoming leaner, etc, whether complimentary or not (115).

8) Up to this point, there was a lack of validated instruments to assess desires/urges for movement and sedentary behavior. However, this gap was just recently addressed with the creation of the CRAVE (Cravings for Rest and Volitional Energy Expenditure) scale to measure desires/wants for movement and sedentary behavior (108). This novel instrument must be further investigated and validated under different conditions (e.g., prolonged sedentary behaviour, different psychological moods, different exercise activities).

9) Future investigations should also be sensitive to linguistic and cultural differences. For instance, how desires, wants, urges and cravings translate in Portuguese might correspond to the words desejo or vontade (desire), querere (want), impulso (urge), necessidade or ânsia (craving) or even saudades - intense desires or longings for almost anything that is missing (142).

10) Utilizing the concepts of desires/urges to move to explain other phenomena of interest. We focus on two examples. First, desires/urges for movement and rest might moderate the relationship between psychological stress and physical activity (62), which seems to fit within the tenets of the AHBF/IF model (11). Second, the development of this concept may also be expanded to inform how energy availability (e.g., overfeeding or a deficit), and more generally nutrition, affects urges to move or be sedentary. For instance, a surplus of calories might result in altered desires to move for some people, which then may influence variations in non-exercise activity thermogenesis (NEAT), particularly spontaneous physical activity (i.e., fidgeting, posture adjustments) $(143,144)$ and other compensatory behaviors $(145)$.

Such considerations provide fodder for a multiplicity of future investigations.

\section{Practical implications}

Understanding the underpinnings that lead to desires/urges for movement or rest may have vast practical implications in fields such as exercise science, motor control, performance, and physical therapy. Unfortunately, up until this time motivation states for movement were overlooked, considered irrelevant or categorized as a nuisance factor other than a real point of possible intervention. For instance, Williams, Rhodes \& Conner (11) did not identify motivation states as a possible route of intervention in their integrated framework. However, given the potential stated above it is reasonable to consider methods that can enhance the desire to move. There are six general approaches relating to desires and urges: 1) To improve movement wants, modifying the reward value of exercise by making it less punishing and/or more pleasurable (increasing the "like"), 2) varying physical activity and exercise to result in less rapid satiation of desires, 3) modifying environmental and situational conditions to either ramp up motivation states to move and/or possibly dampen motivation states for rest, 4) modulating psychological attention to these desires so individuals might be more sensitive/attuned to desires, both noticing them when they occur and acting on them and 5) "nudging" them in response to these noticed 
desires/cravings, particularly with cues $(134,146)$, and 6) taking advantage of urges/desires for other rewarding behaviors to encourage development of desires to move. Regarding this last point, some work is already being done on gamifying movement, making games contingent on moving (e.g., Pokemon) to increase the reward value of movement (147).

It seems sensible to start with this approach of modifying exercise. Can exercise be modulated to make it more rewarding, and thus result in greater "wants"? Exercise can be modified to increase enjoyment by focusing on preferences $(148,149)$ or reduce punishing aspects of exercise, like avoiding eccentric contractions (150) or excessive buildup of lactate and fatigue (e.g., minimized with sprint interval training - SIT) $(151,152)$. It is likely important to avoid sudden, large increases in novel physical activities that result in excessive muscle damage and soreness, which are associated with decreases in physical activity $(153,154)$ and negative shifts in mood $(155,156)$. We could also modify conditions to promote desires so that desires/urges are felt more frequently and/or with greater intensity. For instance, music often leads to muscular movement as humans can sense desires to move in response to a beat (i.e., groove), and musical cues seem to elicit neural firing (157). It is likely that humans can even form internal representations of a beat so that anticipatory movement can occur in preparation for music, which is coordinated by the cerebellum, the supplementary motor area and the pre-motor cortex (157). Motivational videos and other visual images (i.e., highly fit individuals, major sport feats, etc.) may also stimulate improved movement motivation and performance $(158,159)$. Environmental conditions, particularly daylight, can have a significant impact on levels of physical activity (160). While weather cannot be changed, contingency plans can be put into place to modulate desires to move, and thus behavior, in response to varying conditions. One might imagine that it is possible to nearly perfect exercise conditions (e.g., ambient lighting, exercise-related imagery, diet, music, social interactions, acceptable stimulants, like caffeine) to facilitate greater muscular movement. Undoubtedly, coaches, commercial gyms and others already engage in such efforts to create attractive environmental and motivational climates to spur movement and its enjoyment $(161,162)$.

Regarding approach 4, a large literature, starting with Libet (20) demonstrates that even healthy and well-functioning individuals can be trained to pay attention to urges for movement (118). Unfortunately, protocols in these studies have not been used in attempts to facilitate greater movement but were designed to investigate the control of movement. Perhaps simply asking someone about their desires/wants to move can instigate motivation states for movement. In populations suffering from addiction or stress, mindfulness meditation has been used to help individuals sense desires and then "ride the wave", interpreting appetitive stimuli as "mere mental events" as a method to cope with dysfunctional urges (137, 163-165). In line with these advances, perhaps a method, such as mindfulness and/or vivid imagery, could be developed or modified to promote greater movement (18). This might involve generating desires/urges to move or simply paying attention and "listening" to them, thus bringing them fully into conscious awareness, gauging them, and consequently acting or consciously not acting on them $(137,166-$ 170). This approach seems promising but is still theoretical, and its efficacy is unknown.

\section{Conclusion}

We conclude that there is a conceptual basis for desires and urges to motivate human movement and sedentary behavior. Such understanding is still in its infancy, particularly because of numerous similar concepts in literatures isolated from each other and a corresponding lack of 
810 coherence in definitions. Nevertheless, desires and wants for movement appear to be common constructs across multiple relevant theories. The current investigation conceptualizes physical activity primarily as a negative reinforcer. Humans likely have a "need for activity" that varies in intensity across the population $(68,80)$, is not simply a lack of "need to rest", and may be felt as tension when unsatisfied. These salient, internal cues may elicit wants or desires to rest and move, in other words, fluctuating states of motivation to either expend energy or be sedentary. In some situations, or for individuals with certain conditions, desires for activity may be experienced as urges or even cravings (16). This manuscript describes the WANT (Wants and Aversions for Neuromuscular Tasks) model, a circumplex model of wants and urges for movement and rest, where these factors are placed orthogonally. This heuristic might help to inform how movement and rest wants might be observed in a variety of situations. Unfortuantely, no models specific to movement and rest exist to explain both how desires are precipitated and exert influence. Such models should expand beyond the automatic and impulsive level of processing predominately described in this manuscript to include interactions between desires/urges and reflective factors. The AHBF/IF is, perhaps, closest to this proposed model. Up to this point, instrumentation to measure desire has been lacking. However, the recent validation of the CRAVE Scale is an example of an advancement that might facilitate further understanding of why changes in movement and sedentary behavior occur across the day, and how these changes occur. Data generated in this regard may help to understand daily fluctuations in energy expenditure in both healthy, formal functioning populations as well as clinical populations where perception and manifestation of muscular movement is problematic. It is our desire that this this conceptual analysis will provide a starting point for future investigations.

\section{Acknowledgements}

Marcus Kilpatrick, Ph.D. (University of South Florida) and Justin B. Moore, Ph.D. (Wake Forest School of Medicine) provided thoughtful comments on this project in its early stages. We would also like to acknowledge graduate students from Teachers College, Columbia University, who provided many provoking insights.

\section{Funding}

GA is supported by a fellowship from the Office of Academic Affiliations at the United States Veterans Health Administration.

\section{References}

1. Shields C. Aristotle's De Anima, tranlsated with commentary. Oxford2016.

2. $\quad$ Aristotle. De Anima iii. Raleigh, N.C.: Generic NL Freebook Publisher.

3. Nascimento DS. Desire and cognition in Aristotle's theory of the voluntary movements of animal locomotion. Filosofia Unisinos. 2017;18:70-8.

4. Frijda NH. The evolutionary emergence of what we call "emotions". Cognition and Emotion. 2016;30(4):609-20.

5. Rhodes RE, McEwan D, Rebar AL. Theories of physical activity behaviour change: A history and synthesis of approaches. Psychology of Sport and Exercise. 2019;42:100-9.

6. Brand R, Ekkekakis P. Affective-Reflective Theory of physical inactivity and exercise. German Journal of Exercise and Sport Research. 2018;48(1):48-58.

7. Ridderinkhof KR. Emotion in Action: A Predictive Processing Perspective and Theoretical Synthesis. Emotion Review. 2017;9(4):319-25.

8. Frijda NH. Impulsive action and motivation. Biological Psychology. 2010;84(3):570-9. 
9. Williams DM, Evans DR. Current Emotion Research in Health Behavior Science. Emotion Review. 2014;6(3):277-87. 10. Ekkekakis P, Zenko Z. Escape from cognitivism: exercise as hedonic experience. In: M. Raab, P. Wyllemann, R. Seiler, Elbe AM, Hatzigeorgiadis A, editors. Sport and exercise psychology research From theory to practice. Amsterdam: Elsevier; 2016. p. 389-414.

11. Williams DM, Rhodes RE, Conner MT. Conceptualizing and intervening on affective determinants of health behaviour. Psychology \& Health. 2019;34(11):1267-81.

12. Clear J. Atomic Habits: The life-changing million copy bestseller: Random House; 2018. 13. Conroy DE, Berry TR. Automatic Affective Evaluations of Physical Activity. Exerc Sport Sci Rev. 2017;45(4):230-7.

Current Opinion in Neurobiology. 2012;22(6):1004-11.

870 15. Garcia-Borreguero D, Stillman P, Benes H, Buschmann H, Chaudhuri KR, Rodriguez VMG, et 871 al. Algorithms for the diagnosis and treatment of restless legs syndrome in primary care. Bmc Neurology. 872 2011;11:12.

873 16. Ferreira A, Lamarque S, Boyer P, Perez-Diaz F, Jouvent R, Cohen-Salmon C. Spontaneous 874 appetence for wheel-running: a model of dependency on physical activity in rat. European Psychiatry. 875 2006;21(8):580-8.

876 17. Matthews TE, Witek MAG, Heggli OA, Penhune VB, Vuust P. The sensation of groove is 877 affected by the interaction of rhythmic and harmonic complexity. PLoS One. 2019;14(1):e0204539-e. 18. Kavanagh DJ, Andrade J, May J. Imaginary relish and exquisite torture: The elaborated intrusion theory of desire. Psychological Review. 2005;112(2):446-67.

19. Reiss S. Multifaceted nature of intrinsic motivation: The theory of 16 basic desires. Review of General Psychology. 2004;8(3):179-93.

20. Libet B, Gleason C, Wright E, Pearl D. Time of conscious intention to act in relation to onset of cerebral activity (readiness-potential). Brain. 1983;106(3):623-42.

21. Hausenblas HA, Downs DS. Exercise dependence: a systematic review. Psychology of Sport and Exercise. 2002;3(2):89-123.

22. Gernigon C, D'Arripe-Longueville F, Delignieres D, Ninot G. A Dynamical Systems Perspective on Goal Involvement States in Sport. Journal of sport \& exercise psychology. 2004;26:572-96.

23. Ussher MH, Taylor A, Faulkner G. Exercise interventions for smoking cessation. Cochrane Database Syst Rev. 2008(4):Cd002295.

24. Ford ME. Motivating humans : goals, emotions, and personal agency beliefs. Newbury Park, Calif:: Sage Publications; 1992.

25. McDougall W. The energies of men. New York: Scribners; 1933.

26. Hull CL. Principles of behavior: an introduction to behavior theory. New York: AppletonCentury; 1943.

27. Weiner B. Human Motivation. New York: Springer-Verlag; 1982.

28. Lewin K. Field theory in social science. 1951.

29. Marrow AJ, Marrow AJ, Lewin K. The Practical Theorist: The Life and Work of Kurt Lewin: Basic Books; 1969.

30. Karsten A. Psychische Sattigung (Psychological satiety). Psychologische Forscbung (Psychological Research). 1928;10:142-54.

31. Lewin K. The Importance of "Psychological Saturation" for Some Problems in Psychotechnology. In: Psychotechnische Zeitschrift 3 , 182-188. In: Lück H, editor. Kurt Lewin, Writings on Applied Psychology. Vienna: Krammer; 1928/2009.

32. Soff M. From psychological satiety to exhaustion of the will to work. Kurt Lewin and Anitra Karsten as pioneers in burnout research. Gestalt Theory. 2012;33(2):183-200.

33. Niv Y. Cost, benefit, tonic, phasic: what do response rates tell us about dopamine and motivation? Annals of the New York Academy of Sciences. 2007;1104:357-76.

34. Skinner BF. The Behavior of Organisms. New York: Appleton-Century-Crofts; 1938. 
35. Skinner BF, Morse WH. Fixed-interval reinforcement of running in a wheel. Journal of the Experimental Analysis of Behavior. 1958;1(4):371-9.

36. Loewenstein G. Out of control: Visceral influences on behavior. Organizational Behavior and Human Decision Processes. 1996;65(3):272-92.

37. Tiggemann M, Kemps E. The phenomenology of food cravings: The role of mental imagery. Appetite. 2005;45(3):305-13.

38. Salamone JD, Correa M. Motivational views of reinforcement: implications for understanding the behavioral functions of nucleus accumbens dopamine. Behavioural Brain Research. 2002;137(1-2):3-25. 39. Scheurink AJW, Boersma GJ, Nergardh R, Sodersten P. Neurobiology of hyperactivity and reward: Agreeable restlessness in Anorexia Nervosa. Physiology \& Behavior. 2010;100(5):490-5. 40. Shadmehr R, Ahmed AA. Vigor: Neuroeconomics of Movement Control: MIT Press; 2020. 41. Ekkekakis P. Pleasure from the exercising body: Two centuries of changing outlooks in psychological thought. In: Ekkekakis P, editor. Routledge Handbook of Physical Activity and Mental Health. New York: Routledge; 2013. p. 35-56.

42. O'Connor PJ, Cook DB. Exercise and pain: The neurobiology, measurement, and laboratory study of pain in relation to exercise in humans. Exercise and Sport Sciences Reviews. 1999;27:119-66.

43. Stults-Kolehmainen MA, Lu T, Ciccolo JT, Bartholomew JB, Brotnow L, Sinha R. Higher chronic psychological stress is associated with blunted affective responses to strenuous resistance exercise: RPE, pleasure, pain. Psychology of Sport and Exercise. 2016;22:27-36.

44. Garland T, Schutz H, Chappell MA, Keeney BK, Meek TH, Copes LE, et al. The biological control of voluntary exercise, spontaneous physical activity and daily energy expenditure in relation to obesity: human and rodent perspectives. Journal of Experimental Biology. 2011;214(2):206-29.

45. Roberts MD, Gilpin L, Parker KE, Childs TE, Will MJ, Booth FW. Dopamine D1 receptor modulation in nucleus accumbens lowers voluntary wheel running in rats bred to run high distances. Physiology \& Behavior. 2012;105(3):661-8.

46. Belke TW, Pierce WD. Effect of sucrose availability and pre-running on the intrinsic value of wheel running as an operant and a reinforcing consequence. Behavioural Processes. 2014;103:35-42.

47. Collier G, Hirsch E. Reinforcing properties of spontaneous activity in rat. Journal of Comparative and Physiological Psychology. 1971;77(1):155-\&.

48. Schultheiss OC, Wirth MM. Biopsychological aspects of motivation. Motivation and action, 2nd ed. New York, NY, US: Cambridge University Press; 2008. p. $247-71$.

49. Cacioppo JT, Priester JR, Berntson GG. Rudimentary determinants of attitudes. II: Arm flexion and extension have differential effects on attitudes. J Pers Soc Psychol. 1993;65(1):5-17.

50. Cabanac M. Sensory pleasure optimizes muscular work. Clinical and Investigative Medicine. 2006;29(2):110-6.

51. Cabanac M. Exertion and pleasure from an evolutionary perspective. In: Acevedo EO, Ekkekakis P, editors. Psychobiology of Physical Activity. Champaign, IL: Human Kinetics; 2006. p. 79-89.

52. Boecker H, Dishman RK. Physical activity and reward: The role of endogenous opioids. In: Ekkekakis P, editor. Routledge Handbook of Physical Activity and Mental Health. New York: Routledge; 2013. p. 57-70.

53. Panksepp J. Emotional endophenotypes in evolutionary psychiatry. Prog Neuropsychopharmacol Biol Psychiatry. 2006;30(5):774-84.

54. Frijda NH. Emotion, cognitive structure, and action tendency. Cognition and Emotion. 1987;1(2):115-43.

55. Bartholomew JB, Morrison D, Ciccolo JT. Effects of acute exercise on mood and well-being in patients with major depressive disorder. Medicine and Science in Sports and Exercise. 2005;37(12):20327.

56. Dietrich A, McDaniel WF. Endocannabinoids and exercise. British Journal of Sports Medicine. 2004;38(5):536-41. 
959

960

961

962

963

964

965

966

967

968

969

970

971

972

973

974

975

976

977

978

979

980

981

982

983

984

985

986

987

988

989

990

991

992

993

994

995

996

997

998

999

1000

1001

1002

1003

1004

1005

1006

1007

1008

57. Ekkekakis P, Parfitt G, Petruzzello SJ. The Pleasure and Displeasure People Feel When they Exercise at Different Intensities: Decennial Update and Progress towards a Tripartite Rationale for Exercise Intensity Prescription. Sports Medicine. 2011;41(8):641-71.

58. Williams DM, Dunsiger S, Ciccolo JT, Lewis BA, Albrecht AE, Marcus BH. Acute affective response to a moderate-intensity exercise stimulus predicts physical activity participation 6 and 12 months later. Psychology of Sport and Exercise. 2008;9(3):231-45.

59. Rhodes RE, Kates A. Can the Affective Response to Exercise Predict Future Motives and Physical Activity Behavior? A Systematic Review of Published Evidence. Annals of Behavioral Medicine. 2015;49(5):715-31.

60. Ekkekakis P, Hall EE, Petruzzello SJ. Some Like It Vigorous: Measuring Individual Differences in the Preference for and Tolerance of Exercise Intensity. Journal of Sport \& Exercise Psychology. 2005;27(3):350-474.

61. Salmon P. Effects of physical exercise on anxiety, depression, and sensitivity to stress: A unifying theory. Clinical Psychology Review. 2001;21(1):33-61.

62. Stults-Kolehmainen MA, Sinha R. The effects of stress on physical activity and exercise. Sports Medicine. 2014;44(1):81-121.

63. Bartholomew JB, Lewis BP, Linder DE, Cook DB. Post-exercise analgesia: Replication and extension. Journal of Sports Sciences. 1996;14(4):329-34.

64. Thayer RE, Newman JR, McClain TM. Self-regulation of mood: Strategies for changing a bad mood, raising energy, and reducing tension. Journal of Personality and Social Psychology. 1994;67(5):910-25.

65. Ingledew DK, Hardy L, Cooper CL, Jemal H. Health behaviours reported as coping strategies: A factor analytical study. British Journal of Health Psychology. 1996;1:263-81.

66. Endrighi R, Steptoe A, Hamer M. The effect of experimentally induced sedentariness on mood and psychobiological responses to mental stress. Br J Psychiatry. 2016;208(3):245-51.

67. Collier GH. Work- A weak reinforcer. Transactions of the New York Academy of Sciences. 1970;32(5):557-\&.

68. de Geus EJ, de Moor MH. Genes, exercise, and psychological factors. In: Bouchard C, Hoff man EP, editors. Genetic and molecular aspects of sports performance. Oxford: Blackwell Publishing; 2011. p. 294-305.

69. Kalupahana NS, Moustaid-Moussa N, Kim JH, Voy BH, Bassett D, Bray MS, et al. The regulation of physical activity by genetic mechanisms: Is there a drive to be active? In: Bouchard C, Hoffman EP, editors. Genetic and Molecular Aspects of Sport Performance. Hoboken, NJ: John Wiley \& Sons; 2011. p. 283-93.

70. Feige K. Wesen und Problematik der Sportmotivation. Sportunterricht. 1976;5:4-7.

71. Panksepp J, Biven L. The archaeology of mind. Neuroevolutionary origins of human emotions. New York: Norton; 2012.

72. Parker PRL, Brown MA, Smear MC, Niell CM. Movement-Related Signals in Sensory Areas: Roles in Natural Behavior. Trends in Neurosciences. 2020;43(8):581-95.

73. Wilson TD, Reinhard DA, Westgate EC, Gilbert DT, Ellerbeck N, Hahn C, et al. Just think: The challenges of the disengaged mind. Science. 2014;345(6192):75-7.

74. Bain A. The senses and the intellect. London: John W. Parker \& Son; 1855.

75. Baldwin JM. Handbook of Psychology: Feeling and Will. New York: Henry Holt \& Company; 1891.

76. Baldwin JM. Mental development in the child and the race: Methods and processes. New York: Macmillan; 1894.

77. Finger FW, Mook DG. Basic drives. Annual Review of Psychology. 1971;22:1-\&.

78. Hill WF. Activity as an autonomous drive. Journal of Comparative and Physiological Psychology. 1956;49(1):15-9.

79. Shirley M. Spontaneous activity. Psychological Bulletin. 1929;26(6):341-65. 
1009

1010

1011

1012

1013

1014

1015

1016

1017

1018

1019

1020

1021

1022

1023

1024

1025

1026

1027

1028

1029

1030

1031

1032

1033

1034

1035

1036

1037

1038

1039

1040

1041

1042

1043

1044

1045

1046

1047

1048

1049

1050

1051

1052

1053

1054

1055

1056

1057

1058

80. Rowland TW. The biological basis of physical activity. Medicine and Science in Sports and Exercise. 1998;30(3):392-9.

81. James W. The Energies of Men. The Philosophical Review. 1907;16(1):1-20.

82. Levine JA, Lanningham-Foster LM, McCrady SK, Krizan AC, Olson LR, Kane PH, et al. Interindividual variation in posture allocation: Possible rote in human obesity. Science. 2005;307(5709):584-6.

83. Dunk NM, Callaghan JP. Lumbar spine movement patterns during prolonged sitting differentiate low back pain developers from matched asymptomatic controls. Work. 2010;35(1):3-14.

84. Iqbal N, Lambert T, Masand P. Akathisia: Problem of history or concern of today. Cns Spectrums. 2007;12(9):1-+.

85. Willerman L. Activity level and hyperactivity in twins. Child Development. 1973;44(2):288-93. 86. Davis C, Woodside DB. Sensitivity to the rewarding effects of food and exercise in the eating disorders. Compr Psychiatry. 2002;43(3):189-94.

87. Ishizaki Y, Ishizaki T, Fukuoka H, Kim CS, Fujita M, Maegawa Y, et al. Changes in mood status and neurotic levels during a 20-day bed rest. Acta Astronautica. 2002;50(7):453-9.

88. Jarrett OS, Maxwell DM, Dickerson C, Hoge P, Davies G, Yetley A. Impact of recess on classroom behavior: Group effects and individual differences. Journal of Educational Research. 1998;92(2):121-6.

89. Mondin GW, Morgan WP, Piering PN, Stegner AJ, Stotesbery CL, Trine MR, et al.

Psychological consequences of exercise deprivation in habitual exercisers. Medicine and Science in Sports and Exercise. 1996;28(9):1199-203.

90. Berridge KC, Robinson TE. What is the role of dopamine in reward: Hedonic impact, reward learning, or incentive salience? Brain Research Reviews. 1998;28(3):309-69.

91. Robinson TE, Berridge KC. The neural basis of drug craving: An incentive-sensitization theory of addiction. Brain Research Reviews. 1993;18(3):247-91.

92. Roemmich JN, Barkley JE, Lobarinas CL, Foster JH, White TM, Epstein LH. Association of liking and reinforcing value with children's physical activity. Physiology \& Behavior. 2008;93(4-5):10118.

93. Smith KS, Berridge KC. Opioid limbic circuit for reward: Interaction between hedonic hotspots of nucleus accumbens and ventral pallidum. Journal of Neuroscience. 2007;27(7):1594-605.

94. Flack KD, Ufholz K, Johnson L, Roemmich JN. Increasing the Reinforcing Value of Exercise in Overweight Adults. Frontiers in Behavioral Neuroscience. 2019;13(265).

95. Flack K, Pankey C, Ufholz K, Johnson L, Roemmich JN. Genetic variations in the dopamine reward system influence exercise reinforcement and tolerance for exercise intensity. Behavioural Brain Research. 2019;375:112148.

96. Roberts GC. Motivation in Sport and Exercise from an achievement goal perspective: After 30 years, where are we? In: Roberts GC, Treasure D, editors. Advances in Motivation in Sport and Exercise. 3rd ed. Champaign, IL: Human Kinetics; 2012. p. 5-58.

97. Deci EL, Ryan RM. The "what" and "why" of goal pursuits: Human needs and the selfdetermination of behavior. Psychological Inquiry. 2000;11(4):227-68.

98. Deci EL, Ryan RM. Intrinsic motivation and self-determination in human behavior. New York, NY: Plenum Press; 1985.

99. Vallerand RJ. Toward a hierarchical model of intrinsic and extrinsic motivation. Advances in Experimental Social Psychology, Vol 29. 1997;29:271-360.

100. Vallerand RJ, Blais MR, Brière NM, Pelletier LG. Construction et validation de l'échelle de motivation en éducation (EME). Canadian Journal of Behavioural Science / Revue canadienne des sciences du comportement. 1989;21(3):323-49.

101. Teixeira PJ, Carraça EV, Markland D, Silva MN, Ryan RM. Exercise, physical activity, and selfdetermination theory: A systematic review. International Journal of Behavioral Nutrition and Physical Activity. 2012;9(1):78. 
Desire, Urge and State Motivation

1059

1060

1061

1062

1063

1064

1065

1066

1067

1068

1069

1070

1071

1072

1073

1074

1075

1076

1077

1078

1079

1080

1081

1082

1083

1084

1085

1086

1087

1088

1089

1090

1091

1092

1093

1094

1095

1096

1097

1098

1099

1100

1101

1102

1103

1104

1105

1106

1107

1108

1109

102. Strack F, Deutsch R. Reflective and impulsive determinants of social behavior. Personality and social psychology review : an official journal of the Society for Personality and Social Psychology, Inc. 2004;8(3):220-47.

103. Kringelbach M, Kent, C. Motivation and Pleasure in the Brain. In: Hofmann W, Nordgren, L.F., editor. The Psychology of Desire: Guilford Publications; 2016.

104. Lutz RS, Stults-Kolehmainen MA, Bartholomew JB. Exercise caution when stressed: Stages of change and the stress-exercise participation relationship. Psychology of Sport and Exercise.

2010;11(6):560-7.

105. Frijda NH, Kuipers P, ter Schure E. Relations among emotion, appraisal, and emotional action readiness. Journal of Personality and Social Psychology. 1989;57(2):212-28.

106. Frijda NH, Ridderinkhof KR, Rietveld E. Impulsive action: Emotional impulses and their control. Frontiers in Psychology. 2014;5.

107. Beeler JA, Frazier CRM, Zhuang X. Putting desire on a budget: dopamine and energy expenditure, reconciling reward and resources. Frontiers in integrative neuroscience. 2012;6:49.

108. Stults-Kolehmainen MA, Blacutt M, Gilson TA, Stanforth P, Divin AL, Bartholomew JB, et al. I want to move my body - right now! The CRAVE Scale to measure state motivation for physical activity and sedentary behavior. MedrXiv. 2020.

109. Hofmann W, Baumeister RF, Forster G, Vohs KD. Everyday Temptations: An Experience Sampling Study of Desire, Conflict, and Self-Control. Journal of Personality and Social Psychology. 2012;102(6):1318-35.

110. Hofmann W, Van Dillen L. Desire: The New Hot Spot in Self-Control Research. Current Directions in Psychological Science. 2012;21(5):317-22.

111. Hofmann W, Vohs KD, Baumeister RF. What People Desire, Feel Conflicted About, and Try to Resist in Everyday Life. Psychological Science. 2012;23(6):582-8.

112. Papies EK, Barsalou LW. Grounding desire and motivated behavior: A theoretical framework and review of empirical evidence. In: Hofmann W, Nordgren LF, editors. The Psychology of Desire. New York: Guilford Press; 2015.

113. Kavanagh DJ, Andrade J, May J. Imaginary relish and exquisite torture: the elaborated intrusion theory of desire. Psychol Rev. 2005;112(2):446-67.

114. May J, Andrade J, Kavanagh D, Penfound L. Imagery and strength of craving for eating, drinking, and playing sport. Cognition \& Emotion. 2008;22(4):633-50.

115. Katula JA, Sipe M, Rejeski WJ, Focht BC. Strength training in older adults: an empowering intervention. Med Sci Sports Exerc. 2006;38(1):106-11.

116. Matsuhashi M, Hallett M. The timing of the conscious intention to move. Eur J Neurosci. 2008;28(11):2344-51.

117. Fried I, Mukamel R, Kreiman G. Internally generated preactivation of single neurons in human medial frontal cortex predicts volition. Neuron. 2011;69(3):548-62.

118. Lau HC, Rogers RD, Haggard P, Passingham RE. Attention to intention. Science.

2004;303(5661):1208-10.

119. Li N, Chen T-W, Guo ZV, Gerfen CR, Svoboda K. A motor cortex circuit for motor planning and movement. Nature. 2015;519(7541):51-6.

120. Pacherie E, editor The Role of Emotions in the Explanation of Action2005.

121. Elster J. Urgency. Inquiry. 2009;52(4):399-411.

122. Klinger E. Current concerns and disengagement from incentives. In: Halisch F, Kuhl J, editors.

Motivation, Intention and Volition. Berlin: Springer-Verlag; 1987. p. 337-47.

123. Jung Y, Hassan A, St Louis EK, Robertson CE. Restless mouth syndrome. Neurol Clin Pract. 2017;7(3):e29-e30.

124. Ruppert E. Restless arms syndrome: prevalence, impact, and management strategies.

Neuropsychiatr Dis Treat. 2019;15:1737-50.

125. Cavanna AE, Nani A. Tourette syndrome and consciousness of action. Tremor Other Hyperkinet Mov (N Y). 2013;3:tre-03-181-4368-1. 
1110 126. Lang PJ, Bradley MM. Emotion and the motivational brain. Biological Psychology.

$11112010 ; 84(3): 437-50$.

1112 127. Barke A, Baudewig J, Schmidt-Samoa C, Dechent P, Kröner-Herwig B. Neural correlates of fear 1113 of movement in high and low fear-avoidant chronic low back pain patients: an event-related fMRI study.

1114 Pain. 2012;153(3):540-52.

1115 128. Rosenberg H. Clinical and laboratory assessment of the subjective experience of drug craving.

1116 Clin Psychol Rev. 2009;29(6):519-34.

1117 129. Kemps E, Tiggemann M, Martin R, Elliott M. Implicit approach-avoidance associations for 1118 craved food cues. J Exp Psychol Appl. 2013;19(1):30-8.

1119 130. Watson D, Wiese D, Vaidya J, Tellegen A. The two general activation systems of affect:

1120 Structural findings, evolutionary considerations, and psychobiological evidence. Journal of Personality

1121 and Social Psychology. 1999;76(5):820-38.

1122 131. Jean-Richard-dit-Bressel P, Ma C, Bradfield LA, Killcross S, McNally GP. Punishment

1123 insensitivity emerges from impaired contingency detection, not aversion insensitivity or reward 1124 dominance. eLife. 2019;8(e52765).

1125 132. Guttman L. A new approach to factor analysis: the Radex. Mathematical thinking in the social

1126 sciences. New York, NY, US: Free Press; 1954. p. 258-348.

1127 133. Acton GS, Revelle W. Interpersonal Personality Measures Show Circumplex Structure Based on

1128 New Psychometric Criteria. Journal of Personality Assessment. 2002;79(3):446-71.

1129 134. Hofmann W, Kotabe, H.P, Vohs, K.D., Baumeister, R.F. Desire and Desire Regulation. In:

1130 Hofmann W, Nordgren, L.F., editor. The Psychology of Desire. New York: Guilford Publications; 2015.

1131 p. 61-81.

1132 135. Greenwood BN, Fleshner M. Voluntary wheel running: a useful rodent model for investigating

1133 mechanisms of stress robustness and exercise motivation. Current Opinion in Behavioral Sciences.

1134 2019;28:78-84.

1135 136. Dholakia UM. Three senses of desire in consumer research. In: Hofmann W, Nordgren LF, editors. The Psychology of Desire. New York: Guilford; 2015. p. 407-31.

137. Papies EK, Barsalou LW, Rusz D. Understanding Desire for Food and Drink: A GroundedCognition Approach. Current Directions in Psychological Science. 2020;29(2):193-8.

138. Andrade J, May J, van Dillen L, Kavanagh DJ. Elaborated Intrustion Theory: Explaining the cognitive and motivational basis of desire. In: Hofmann W, Nordgren LF, editors. The Psychology of Desire. New York: Guilford; 2015. p. 17-35.

139. Bitterly TB, Mislavsky R, Dai H, Milkman KL. Want-should conflict: A synthesis of past research. In: Hofmann W, Nordgren LF, editors. The Psychology of Desire. New York: Guilford; 2015. p. 244-64.

140. deRidder DT, de Witt Huberts, J.C., Evers, C. License to Sin: Reasoning Processes in Desire. In: Hofmann W, Nordgren, L.F., editor. The Psychology of Desire: Guilford Publications; 2015.

141. Coyne KS, Gale Harding G, Jumadilova Z, Weiss JP. Defining urinary urgency: Patient descriptions of "gotta go". Neurourology and urodynamics. 2012;31(4):455-9.

142. Neto F, Mullet E. A Prototype Analysis of the Portuguese Concept of Saudade. Journal of CrossCultural Psychology. 2014;45(4):660-70.

143. Levine JA, Eberhardt NL, Jensen MD. Role of Nonexercise Activity Thermogenesis in Resistance to Fat Gain in Humans. Science. 1999;283(5399):212-4.

144. Rosenbaum M, Leibel RL. Models of energy homeostasis in response to maintenance of reduced body weight. Obesity (Silver Spring). 2016;24(8):1620-9.

145. King NA, Caudwell P, Hopkins M, Byrne NM, Colley R, Hills AP, et al. Metabolic and behavioral compensatory responses to exercise interventions: Barriers to weight loss. Obesity.

1158 146. Thaler RH, Sunstein CR. Nudge: Improving Decisions about Health, Wealth, and Happiness:

1159 Yale University Press; 2008. 
Desire, Urge and State Motivation

1160 147. Kaczmarek LD, Misiak M, Behnke M, Dziekan M, Guzik P. The Pikachu effect: Social and

1161

1162

1163

1164

1165

1166

1167

1168

1169

1170

1171

1172

1173

1174

1175

1176

1177

1178

1179

1180

1181

1182

1183

1184

1185

1186

1187

1188

1189

1190

1191

1192

1193

1194

1195

1196

1197

1198

1199

1200

1201

1202

1203

1204

1205

1206

1207

1208

1209 health gaming motivations lead to greater benefits of Pokémon GO use. Computers in Human Behavior. 2017;75:356-63.

148. Stults-Kolehmainen MA, Ciccolo JT, Bartholomew JB, Seifert J, Portman RS. Age and Genderrelated Changes in Exercise Motivation among Highly Active Individuals. Athletic Insight. 2013;5(1):4563.

149. Busch AM, Ciccolo JT, Puspitasari AJ, Nosrat S, Whitworth JW, Stults-Kolehmainen M. Preferences for Exercise as a Treatment for Depression. Mental Health and Physical Activity. 2016;10:68-72.

150. Kerksick C, Thomas A, Campbell B, Taylor L, Wilborn C, Marcello B, et al. Effects of a popular exercise and weight loss program on weight loss, body composition, energy expenditure and health in obese women. Nutr Metab (Lond). 2009;6:23-.

151. Benitez Flores S, Sousa A, Totó E, Rosa T, Del Rosso S, Foster C, et al. Shorter sprints elicit greater cardiorespiratory and mechanical responses with less fatigue during time-matched sprint interval training (SIT) sessions. Kinesiology. 2018;50.

152. de Sousa AFM, Medeiros AR, Benitez-Flores S, Del Rosso S, Stults-Kolehmainen M, Boullosa DA. Improvements in Attention and Cardiac Autonomic Modulation After a 2-Weeks Sprint Interval Training Program: A Fidelity Approach. Frontiers in Physiology. 2018;9(241).

153. Proske U. Muscle tenderness from exercise: mechanisms? J Physiol. 2005;564(Pt 1):1-.

154. Stults-Kolehmainen MA, Bartholomew JB, Sinha R. Chronic psychological stress impairs recovery of muscular function and somatic sensations over a 96-hour period. J Strength Cond Res. 2014;28(7):2007-17.

155. O'Connor PJ, Morgan WP, Raglin JS. Psychobiologic effects of $3 \mathrm{~d}$ of increased training in female and male swimmers. Medicine \& Science in Sports \& Exercise. 1991;23:1055-61.

156. Stults-Kolehmainen MA, Bartholomew JB. Psychological Stress Impairs Short-Term Muscular Recovery from Resistance Exercise. Medicine and Science in Sports and Exercise. 2012;44(11):2220-7. 157. Levitin DJ, Grahn JA, London J. The Psychology of Music: Rhythm and Movement. Annu Rev Psychol. 2018;69:51-75.

158. Barwood MJ, Weston NJV, Thelwell R, Page J. A motivational music and video intervention improves high-intensity exercise performance. J Sports Sci Med. 2009;8(3):435-42.

159. Cope K, Vandelanotte C, Short CE, Conroy DE, Rhodes RE, Jackson B, et al. Reflective and Non-conscious Responses to Exercise Images. Frontiers in psychology. 2018;8:2272-.

160. Tucker P, Gilliland J. The effect of season and weather on physical activity: A systematic review. Public Health. 2007;121(12):909-22.

161. Bird JM, Karageorghis CI. A Grounded Theory of Music-Video Use in an Exercise Facility. Research Quarterly for Exercise and Sport. 2020;91(3):445-59.

162. Shaulov N, Lufi D. Music and Light during Indoor Cycling. Perceptual and Motor Skills. 2009;108(2):597-607.

163. Papies EK, Pronk TM, Keesman M, Barsalou LW. The benefits of simply observing: mindful attention modulates the link between motivation and behavior. J Pers Soc Psychol. 2015;108(1):148-70.

164. Braun TD, Park CL, Conboy LA. Psychological Well-Being, Health Behaviors, and Weight Loss Among Participants in a Residential, Kripalu Yoga-Based Weight Loss Program. INTERNATIONAL JOURNAL OF YOGA THERAPY. 2012;22:9-22.

165. Jastreboff AM, Chaplin TM, Finnie S, Savoye M, Stults-Kolehmainen M, Silverman WK, et al. Preventing Childhood Obesity Through a Mindfulness-Based Parent Stress Intervention: A Randomized Pilot Study. The Journal of Pediatrics. 2018;202:136-42.e1.

166. Keesman M, Aarts H, Vermeent S, Häfner M, Papies EK. Consumption Simulations Induce Salivation to Food Cues. PLoS One. 2016;11(11):e0165449.

167. Devereaux C. Psychology Today [Internet]2013. [cited 2020 September 29, 2020]. Available from: https://www.psychologytoday.com/us/blog/meaning-in-motion/201306/movement-and-rest. 
1210 168. Renner F, Murphy FC, Ji JL, Manly T, Holmes EA. Mental imagery as a "motivational amplifier" 1211 to promote activities. Behaviour Research and Therapy. 2019;114:51-9.

1212 169. Stults-Kolehmainen M, Malcolm LR, DiLoreto J, Gunnet-Shoval K, Rathbun EI. Psychological

1213 Interventions for weight management: A Primer for the Allied Health Professional. ACSMS Health Fit J.

1214 2015;19(5):16-22.

1215 170. Naves-Bittencourt W, Mendonça-de-Sousa A, Stults-Kolehmainen M, Fontes E, Córdova C,

1216 Demarzo M, et al. Martial Arts: Mindful exercise to combat stress. European Journal of Human

1217 Movement. 2015;34:34-51.

1218

1219

1220

1221

1222

1223

1224

1225

1226

1227

1228

1229

1230

1231

1232

1233

1234

1235

1236

1237

1238

\section{Figure Captions}

Figure 1. Venn diagram illustration of some affectively-charged motivation states (ACMS; urges, wants, appetence, groove, desires and action impulses) as they vary by specificity to muscular movement and valence of the tension. Some concepts originated with movement (i.e., groove, appetence) while others are generally applicable to a multitude of reinforceable behaviors. Circle size denotes degree to which the state covers multiple quadrants. Thickness of circle line denotes prevalence of theme in current literature. [Not all ACMS constructs are included.]

Figure 2. Want/urge motivation states specific to the domains of movement and inactivity behaviors: Approach/avoidance orientation vs Intensity. This is a simple categorical model preceding the model described in Figure 3. * Singular and plural for impulses and dread (multiple instances of dread).

Figure 3. WANT (Wants and Aversions in Neuromuscular Tasks) circumplex model of affectively-charged motivation states (ACMS, i.e., wants, urges, aversions and dread) to move and rest. Interactions between these factors are associated with a variety of situations, emotions and psychological phenomena. 